\title{
Phonological awareness in children with Down syndrome
}

\author{
Helen Fletcher ' and Sue Buckley I, 2 \\ ' Department of Psychology, University of Portsmouth, UK \\ ${ }^{2}$ Down Syndrome Educational Trust, Portsmouth, UK
}

\begin{abstract}
Research in the area of phonological awareness has mainly focused on the nature of the relationship between reading ability and awareness of phonemes. However, a recent study of phonological awareness in children with Down syndrome questioned the existence of any necessary relationship (Cossu, Rossini \& Marshall, 1993). This paper describes a study of phonological awareness in children with Down syndrome with varying levels of reading ability. The sample consisted of 10 male and 7 female children with Down syndrome (aged 9 years 2 months to 14 years 5 months). All children received a battery of tests which consisted of assessments of: I) phonological awareness, 2) reading and spelling competence, 3) non-word reading and spelling ability, and 4) non-verbal measures. Children with Down syndrome demonstrated measurable levels of phonological awareness. Significant positive correlations were found between phonological awareness and: reading and spelling competence, ability to spell non-words and non-verbal measures.
\end{abstract}

Keywords - Phonological awareness, phoneme awareness, reading, alphabetic reading, reading instruction, Down syndrome

\section{Phonological awareness and reading in typical development}

Phonological awareness refers to an individual's overt knowledge of the sound structure of language. Tests of phonological awareness aim to measure the ability to make judgements about, or manipulate the sound structure of words. Observations of typically developing children suggest that phoneme awareness typically emerges at around 5 to 6 years of age, when children learn to read and spell (Gathercole \& Baddeley, 1993). Bradley and Bryant (1985) report a positive association between children's levels of phonological awareness and their reading and spelling ability.

There are three causal hypotheses about the nature of this relationship. Phonological awareness skills may help children learn to read (Bryant \& Bradley, 1985), they may develop as a consequence of the child learning to read (Morais, Cary, Alegria \& Bertelson, 1979), or there may be a reciprocal relationship between these two abilities (Gathercole \& Baddeley, 1993). Children with reading difficulties have been found to fail on tasks of phonological awareness and poor awareness of phonemes has been found to correlate with auditory short term memory deficits and poor reading ability (Gathercole \& Baddeley, 1993).

\section{Reading acquisition of children with Down syndrome}

Children with Down syndrome have been found to experience problems in acquiring language and reading skills and it has been suggested that they may learn to read using a different strategy to typically developing children (Buckley, Emslie, Haslegrave \& LePrevost, 1986). This suggestion was based on the observation that children with Down syndrome commonly make semantic reading errors, suggesting that they use a logographic rather than an alphabetic/ phonological reading strategy. Seymour and Elder (1986) report that typically developing children also produce semantic errors when first learning to read. This evidence suggests that typically developing children also rely on a logographic strategy before developing an alphabetic and then orthographic strategy in their language acquisition (Frith, 1985). However, it seems that children with Down syndrome remain dependent on this strategy for an unusually long time, suggesting that they have difficulty acquiring an alphabetic reading strategy (Byrne, 1997). 


\section{Phonological awareness in children with Down syndrome}

In the past controversial issues in phonological awareness research focused on methods of measurement and the relationship between phonological awareness and reading (Morais et al, 1979; Bradley \& Bryant, 1985; Read, Zhang, Nie \& Ding, 1986; Yopp, 1988; Gathercole \& Baddeley, 1993). However, this changed with the publication of a study that questioned the existence of any necessary relationship between reading and awareness of phonemes (Cossu, Rossini \& Marshall, 1993). Cossu et al. (1993) found that children with Down syndrome were significantly poorer in performance on tasks of phonological awareness than a reading aged matched group of children. Thus they concluded that the children had learnt to read in the absence of phonological awareness. Evans (1994) carried out a study of phonological awareness and reading in six children with Down syndrome and also reported exceptionally poor performance on tasks of phonological awareness relative to reading performance.

Evidence has been presented (Cardoso-Martins and Frith, 1997; Fowler, Doherty \& Boynton, 1995; Cupples and Iacono, 2000) challenging the findings of Cossu et al. (1993) and Evans (1994). They found that although the majority of children with Down syndrome performed poorly on tasks of phonological awareness, some children demonstrated near perfect scores. Byrne (1993) and Morton and Frith (1993) write that research in this area has used tasks of phonological awareness which put too much strain on the cognitive abilities of children with Down syndrome. Therefore they suggest that the children achieve low scores because of extraneous factors such as poor attention or short term memory skills rather than a lack of phonological awareness per se.

A recent study by Cupples and Iacono (2000) used tasks of phonological awareness designed specifically for administration to children with Down syndrome. Keeping in mind the difficulties these children experience with auditory short term memory (see Jarrold \& Baddeley, 2001), the task materials were presented visually to provide a permanent signal which is not subject to decay. Children were not required to give verbal responses for the majority of the tasks but responded by pointing to 1 of 2 target picture cards. Words of 2-4 phonemes were used in the tests, to keep within the digit span of the children.

The current study provides further information on phonological awareness in children with Down syndrome using assessments designed specifically for children with poor auditory short term memory skills and difficulty in producing verbal responses (based on tasks by Cupples \& Iacono, 2000). This paper also examines a range of factors to examine the relationship between phonological awareness and 1) reading and spelling of words and non-words and 2) auditory short term memory.

In view of previous findings, it is expected that:
- Literate children with Down syndrome will demonstrate measurable levels of phonological awareness

- Awareness of phonemes will be seen to have a positive relationship with reading and spelling ability, nonword skills and auditory short term memory skills

\section{Method}

\section{Design}

A within-subjects design was used to study phonological awareness and related factors in children with Down syndrome. All participants received the same battery of assessments.

\section{Participants}

The sample consisted of 17 children with Down syndrome, (10 male, 7 female). The ages of the participants ranged from 9 years 2 months to 14 years 5 months (mean age 12 years 2 months). The main prerequisite concerning selection was that the children had reading ages of approximately 7 years, as it is at this stage in development that most children have been observed to succeed in tasks of phonological awareness.

The participants were recruited through the Sarah Duffen Centre, Portsmouth. All the participants were involved in a longitudinal study of reading development (Byrne, 1997). The main distinctive feature of the sample of children was that they had all attended mainstream primary schools and were known to have received early reading instruction.

\section{Procedure}

Tests were administered to each participant within a twohour testing session at the Sarah Duffen Centre.

A battery of standardised tests was administered to assess reading and spelling competence and non verbal abilities. Each child was assessed using: British Ability Scales (BAS) Word Reading Test A, BAS Spelling Test, Wechsler Objective Reading Dimensions (WORD) Comprehension subtest and BAS Recall of Digits.

A battery of non-standardised tests were administered to assess reading and spelling strategies and phonological awareness. These are briefly described below.

The Seymour reading task (Seymour \& Elder, 1986) assesses the reading strategies used by the child and comprises of six lists of 1) Content words, 2) Functor words, 3) Non-words 4) Irregular words 5) Regular words and 6) Rule words. Content and Functor word reading assess the logographic reading process, Nonword reading assesses alphabetic reading processes and Irregular, Regular and Rule word reading assess knowledge of specific reading rules and alphabetic strategy. The words were presented on flashcards in a random order and the responses taperecorded and then transcribed to allow analysis of errors.

A test of non-word spelling was devised from Seymour's non-word list (Seymour \& Elder, 1986). The children were told that they were going to hear some silly words, and were asked to try and spell them. The children were encouraged 
to first repeat each of the 10 non-words to ensure that they could hear the word correctly. They were then encouraged to try and spell each word. The word was repeated as many times as was required by each child.

\section{Measures of phonological awareness}

Four tasks of phonological awareness were devised (based on tasks by Cupples \& Iacono, 2000), to test the children's awareness of rhyme, and alliteration, and their ability to blend and segment phonemes. The tests were administered using coloured picture cards from the LDA phonological awareness pack 'Sound Beginnings' (Gross \& Garnett, 1995). The picture cards illustrated words which the children would be familiar with, such as 'hat', 'dog' and 'boat'. All words consist of no more than four phonemes to prevent exceeding the digit spans of the children.

1) Rhyme Task: The children were presented with two picture cards and asked to point to the card which rhymed with a word presented verbally. For example, children were presented with pictures of a tent and a boat and told 'This is a 'tent' and this is a 'boat'; show me the one which rhymes with 'coat'.' The children received four practise items on which feedback was given and then 12 test trials with no feedback. The cards were presented so that the position of the target card alternated from right to left. This ensured that children could not achieve high scores through pointing to the same card position each time. In 6 of the trials the non-rhyming card differed from the rhyming pairs at the final phoneme and in the other 6 trials at the middle phoneme. The responses of the children were recorded as correct or incorrect, and a note made of whether the child appeared to comprehend task requirements or was making guesses.

2) Alliteration Task: The children were presented with two picture cards and asked to point to the picture which started with the same sound as the verbally presented word. For example, whilst presenting the cards, the assessor said: 'This is a 'bat' and this is a 'nose'; show me the one that starts the same as 'book'. The children were given four practise trials with feedback, and then 11 test trials without feedback. Again, the target card was presented on alternate sides and the response given recorded.

3) Phoneme Blending: Children were presented with a picture card and the three sounds in the word were spoken by the tester whilst the corresponding letters were placed below the picture (letters were presented for the practise trials only). The children were asked to combine the sounds to make the word that matched the picture card. The children were then told that they were going to hear some more words said in the same way and that they should put the sounds together in their head and point to the picture of the word. For example, pictures of a 'bat' and a 'bus' were presented with the verbal stimulus 'b-u-s'. On each trial both picture cards began with the same sound; this was to ensure that the children were discriminating all the sounds in the word rather than simply the first sound. Again, the position of the target card was alternated from right to left, and the responses recorded on the response sheet. Children were given 2 practise attempts with feedback and then 10 test trials without feedback.

4) Phoneme Segmentation Task: The tester presented the children with a picture card along with the corresponding spoken stimulus. The children were asked if they could tell the tester the sounds in the word. Children were encouraged to say the word very slowly to determine the sounds. The letters which form the word were placed below the picture as the tester said each sound (letters were presented for the practise trials only). The children were encouraged to say the sounds along with the tester. Two practise attempts were allowed with feedback, and then 10 test trials were administered without feedback. Responses were recorded with lower case letters depicting sounds and upper case letters depicting that the child spelt the word rather than sounding it.

The additional variable of BAS Reading Progress (current BAS word reading raw scores minus previous BAS word reading raw scores) was computed using longitudinal data collected by Byrne (1997) five years prior to the current study. This value demonstrates the reading progress made (raw scores) from year one of Byrne's (1997) data collection to the time of the current study. Given the hypothesis that awareness of phonemes aids reading ability, (Bryant \& Bradley, 1985) it was thought that those children making the greatest reading progress may demonstrate better awareness of phonemes. The measure of reading progress was included in the correlational analyses to determine any relationship between word reading progress and phonological awareness.

\section{Results}

Descriptive results of children's raw scores on all tests administered are illustrated in Table 1. Standard and age equivalent scores are included in text when appropriate to provide an example of the extent to which the children with Down syndrome are delayed in comparison to their peer group.

\section{Measures of reading and spelling ability}

All 17 children attempted the BAS reading, BAS spelling and WORD Comprehension tests. Table 1 indicates that scores on the BAS reading task ranged from 5-69; reading age range: 5 years 5 months to 9 years ( $S D=22$ months). The mean score was 38.94 which is equivalent to a reading age of 7 years 2 months. The mean BAS spelling score was 6.00 (age equivalence $=7$ years 2 months). Raw scores ranged from $0-14$; spelling age range $<6$ years to 9 years 11 months $(S D=3.98$ months $)$. The mean score for the WORD comprehension task was 6.65 (age equivalence $=6$ years 3 months). The raw scores ranged from $0-16$; comprehension age $<6$ years to 7 years 9 months $(S D=5.48$ months).

The children were, therefore, making quite good progress with their literary skills. Reading comprehension tended to be behind reading and spelling ability, but this is the usual 


\begin{tabular}{|c|c|c|c|c|c|c|}
\hline & $\mathbf{N}$ & $\mathbf{N}$ scoring zero & Range & $\mathbf{N}$ at ceiling & Mean & Std. Dev. \\
\hline Chronological age (months) & 17 & - & $110.00-173.00$ & - & 137.18 & 15.37 \\
\hline \multicolumn{7}{|l|}{ Reading and spelling tasks } \\
\hline BAS Word Reading & 17 & - & $5.00-69.00$ & - & 38.94 & 22.00 \\
\hline BAS Word Reading - Gain & 16 & - & $5.00-46.00$ & - & 21.56 & $\mid 1.51$ \\
\hline BAS Word Spelling & 17 & 1 & $0-14.00$ & - & 6.00 & 3.98 \\
\hline Seymour Content Word Reading & 16 & I & $0-10.00$ & 5 & 7.25 & 3.36 \\
\hline Seymour Functor Word Reading & 16 & 2 & $0-10.00$ & 3 & 6.19 & 3.37 \\
\hline Seymour Irregular Word Reading & 14 & I & $0-10.00$ & 3 & 6.00 & 3.51 \\
\hline Seymour Regular Word Reading & 14 & - & $1.00-10.00$ & 4 & 6.93 & 3.15 \\
\hline Seymour Rule Word Reading & 14 & I & $0-10.00$ & 2 & 6.43 & 3.30 \\
\hline Seymour Nonword Reading & 15 & 4 & $0-9.00$ & - & 3.40 & 3.16 \\
\hline Nonword Spelling & 17 & 10 & $0-5.00$ & - & 1.18 & 1.74 \\
\hline WORD Comprehension & 17 & 3 & $0-16.00$ & - & 6.65 & 5.48 \\
\hline \multicolumn{7}{|l|}{ Tasks of phonological awareness } \\
\hline Rhyme Task & 14 & - & $6.00-12.00$ & I & 7.57 & 1.74 \\
\hline Alliteration Task & 14 & - & $5.00-11.00$ & 3 & 8.07 & 2.23 \\
\hline Blending Task & 14 & - & $6.00-10.00$ & 3 & 8.50 & 1.29 \\
\hline Segmentation Task & 14 & 6 & $0-6.00$ & - & 1.79 & 2.04 \\
\hline \multicolumn{7}{|l|}{ Short-term memory measure } \\
\hline BAS Recall of Digits & 17 & - & $5.00-16.00$ & - & 9.29 & 3.04 \\
\hline
\end{tabular}

pattern for children with Down syndrome and probably the result of significant language comprehension delay for age.

The five Seymour reading tasks of Content, Functor, Regular, Irregular and Rule words were attempted by 14 of the 17 participants. The maximum score for each of the four tasks was 10 marks. Several children scored full marks on each of these tasks, while one or two children were unable to score. However, the group means indicate that the children performed quite well on these tasks.

\section{Measures of non-word reading and spelling}

The Seymour non-word reading task was attempted by 15 of the 17 children and 4 were unable to score at all. All 17 attempted the Seymour non-word spelling task, but 10 were unable to achieve a score. The maximum score for both tasks was 10 . Table 1 shows that the mean score on the Seymour reading task was 3.4. The scores ranged from 0-9 and the Standard Deviation was 3.16. The mean Seymour non-word spelling score was 1.18; with a range of $0-5$ and a Standard Deviation of 1.74. The children clearly found these tasks, designed to assess their alphabetic skills, much more difficult than the word reading tasks.

\section{Short-term memory measure}

A mean of 9.29 was found for the BAS recall of digits (raw score), and this shows a mean span of 3 digits. Raw scores on this task ranged from 5-16 with a Standard Deviation of 3.04 .

\section{Phonological awareness}

The four tasks of rhyme, alliteration, blending and segmentation were attempted by 14 of the 17 children. The maximum score possible for the rhyme task was 12 marks, for alliteration 11 marks, and for the blending and segmentation tasks 10 marks. The tasks of rhyme, alliteration and blending require the child to point to one of two picture cards in response to each question. Therefore, these tasks carry a 'chance factor' whereby the children have a one in two chance of answering correctly.

Table 1 illustrates mean scores and range of scores for the four tasks of phonological awareness. All children achieved a score on the rhyme, alliteration and blending tasks, and a few children achieved full marks. The mean score for rhyme was 7.57. The scores ranged from $6-12(S D=1.74)$. The mean alliteration score was 8.07 ( range $=5-11, S D=2.23$ ). The mean score for the blending task was 8.5 (range $=$ $6-10, S D=1.29$ ) The segmentation task was clearly much more difficult for the children, with 6 unable to achieve a score. The mean score for segmentation was 1.79 (range $=$ $0-6, S D=2.04$ ).

Children scored highest on measures of blending and alliteration, then rhyme, and performed relatively poorly on the segmentation task. All of the mean scores are above chance level. Six children scored above chance levels on all tasks, five children scored above chance on two of the three tasks with a chance factor, two children scored above chance levels on one task and only one child scored at chance level on all three tasks. 


\begin{tabular}{|c|c|c|c|c|}
\hline & Rhyme & Alliteration & Blending & Segmentation \\
\hline Alliteration & .36 & - & $.63^{* *}$ & -.29 \\
\hline Blending & .34 & $.63^{* * *}$ & - & .22 \\
\hline Segmentation & -.29 & .22 & .22 & - \\
\hline $\begin{array}{l}\text { BAS Word } \\
\text { Reading }\end{array}$ & .45 & .39 & $.61^{*}$ & .25 \\
\hline $\begin{array}{l}\text { BAS Reading } \\
\text { Progress }\end{array}$ & .39 & .19 & $.46^{*}$ & -.22 \\
\hline $\begin{array}{l}\text { BAS Word } \\
\text { Spelling }\end{array}$ & -.01 & .28 & $.52 *$ & .27 \\
\hline $\begin{array}{l}\text { Seymour } \\
\text { Content } \\
\text { Word Reading }\end{array}$ & $.47 *$ & $.46 *$ & $.62 * *$ & .15 \\
\hline $\begin{array}{l}\text { Seymour } \\
\text { Functor } \\
\text { Word Reading }\end{array}$ & $.50 *$ & .28 & $.67^{* * *}$ & .01 \\
\hline $\begin{array}{l}\text { Seymour } \\
\text { Irregular } \\
\text { Word Reading }\end{array}$ & .38 & .17 & $.51^{*}$ & .01 \\
\hline $\begin{array}{l}\text { Seymour } \\
\text { Regular } \\
\text { Word Reading }\end{array}$ & .30 & .31 & $.7 I^{* *}$ & .19 \\
\hline $\begin{array}{l}\text { Seymour Rule } \\
\text { Word Reading }\end{array}$ & .41 & .3 & $.56 *$ & .19 \\
\hline $\begin{array}{l}\text { Seymour } \\
\text { Nonword } \\
\text { Reading }\end{array}$ & .13 & -.03 & .43 & .03 \\
\hline $\begin{array}{l}\text { Nonword } \\
\text { Spelling }\end{array}$ & .11 & .27 & $.52^{*}$ & .19 \\
\hline WORD Comp & $.65^{* * *}$ & $.54 *$ & $.52 *$ & -.09 \\
\hline $\mathrm{CA}$ & -.15 & .09 & .11 & $.64^{* * *}$ \\
\hline $\begin{array}{l}\text { BAS Recall } \\
\text { of Digits }\end{array}$ & -.16 & $.51 *$ & .4 & .34 \\
\hline \multicolumn{5}{|c|}{$\mathrm{p}<.05 * * * 10.01$} \\
\hline
\end{tabular}

The scores on the first 3 tasks provide evidence of significant phonological awareness skills in this group of children.

\section{Correlational analyses}

Pearson's product-moment correlation analyses (one-tailed) were applied to all factors to investigate relationships between phonological awareness and: reading and spelling of words and nonwords, reading progress and non-verbal measures. The correlations are reported in Table 2 .

The figures indicate that rhyme is significantly correlated with Seymour content and functor word reading, and Word comprehension. Alliteration is significantly correlated with blending, Seymour content word reading and Word comprehension.

In contrast, blending is significantly correlated with all the reading measures, with Word comprehension and with non-word spelling. It is positively correlated with non-word reading $(0.43)$ but this does not reach statistical significance.

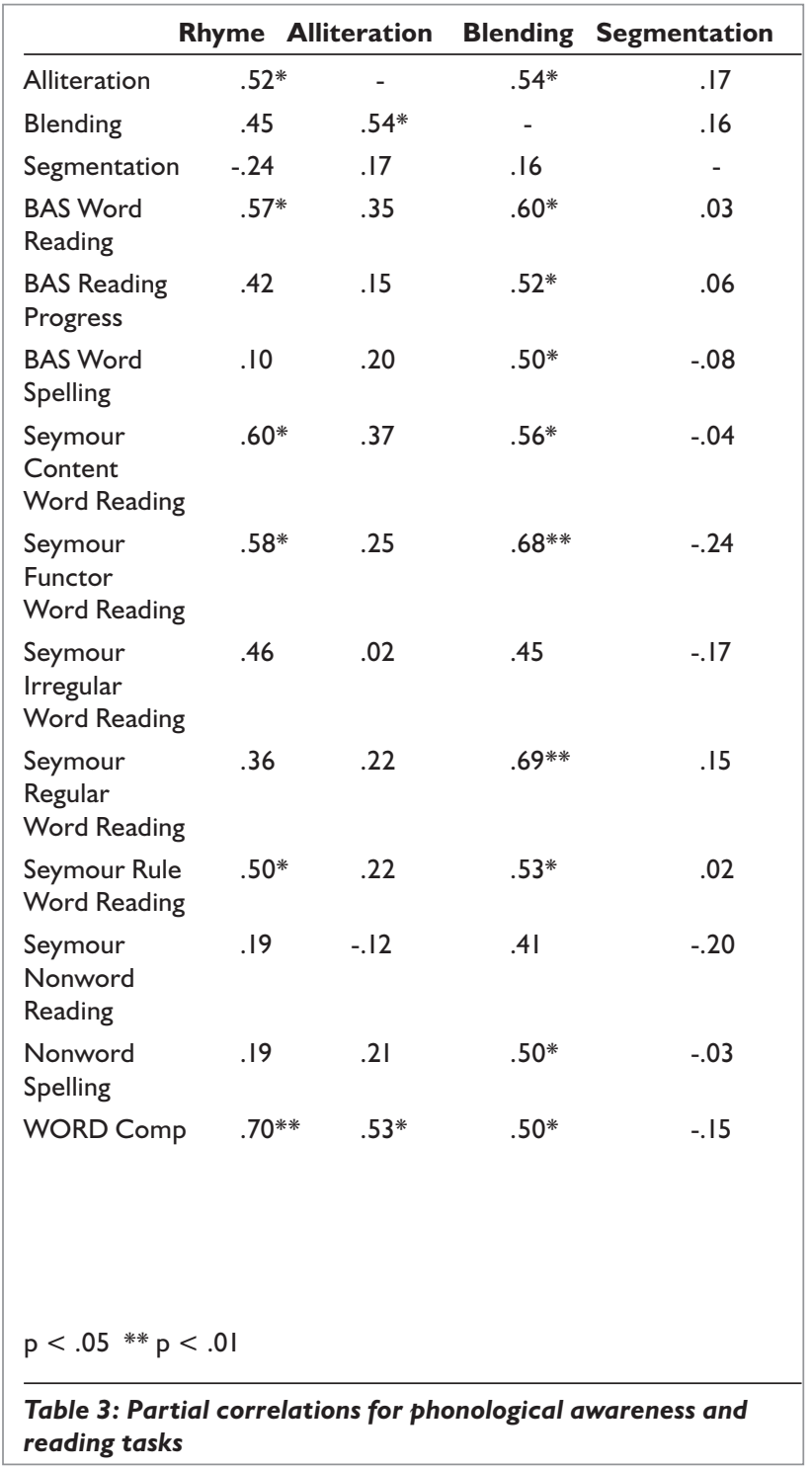

The correlations for segmentation scores and non-word spelling are included for completeness but as the numbers of children who were able to score and the range of scores achieved were so limited these correlations should be interpreted with caution.

\section{Partial correlation analyses}

Partial correlations were carried out (controlling for age and digit span) to investigate whether correlations were dependent on general abilities in addition to reading and spelling competence. The partial correlations show essentially the same picture as the initial correlations. The only significant changes are for rhyme, which now shows significant correlations with alliteration, BAS word reading and Seymour rule word reading, in addition to Seymour content word reading, functor word reading and WORD comprehension. Blending now shows a significant correlation with non-word spelling. Results from the partial analyses are presented in Table 3. 


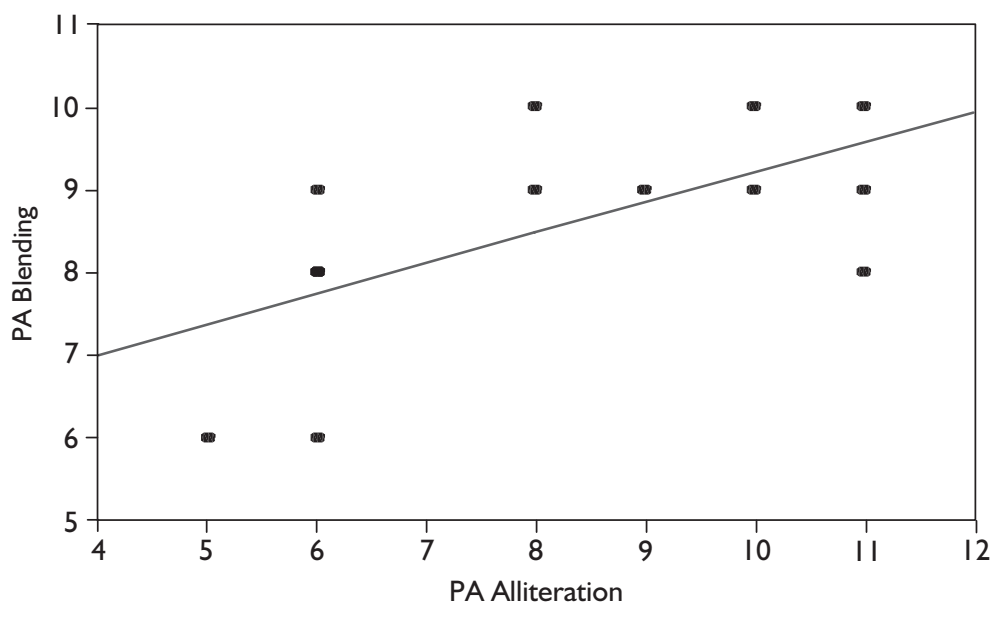

Figure I. Relationship between alliteration and blending tasks

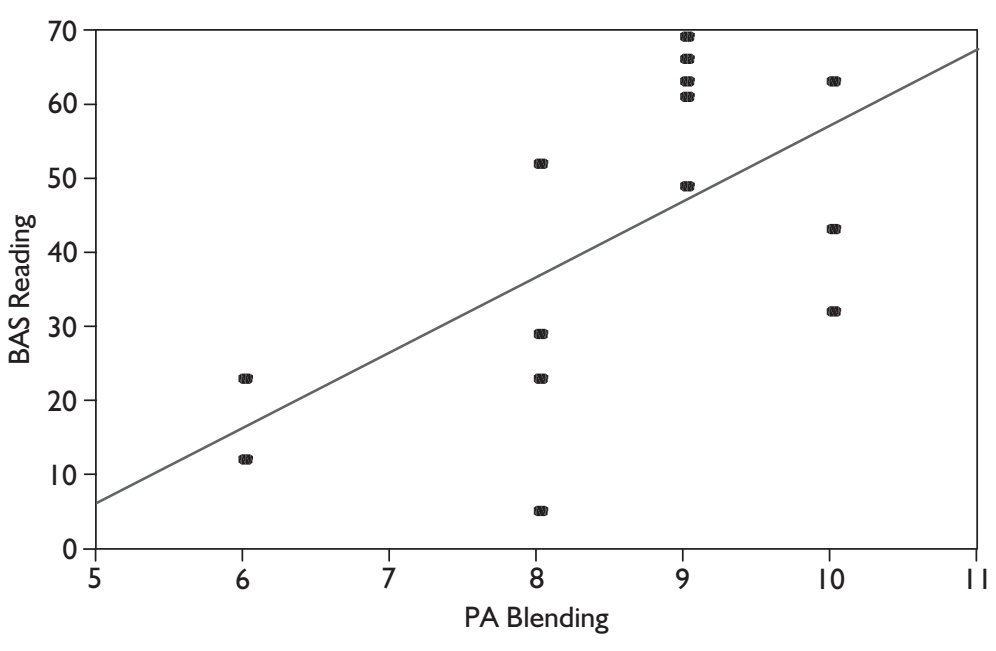

Figure 2. Relationship between blending and BAS reading tasks

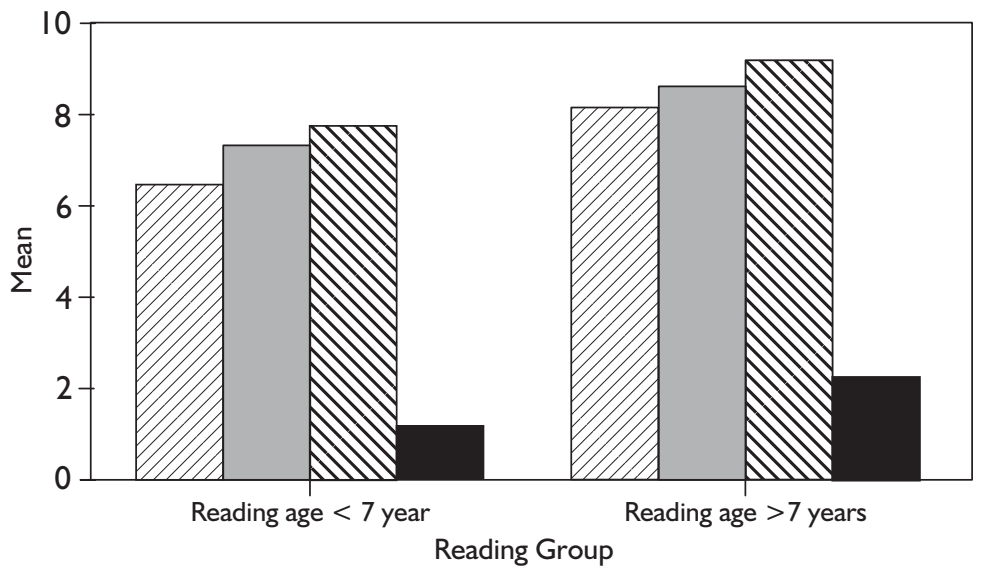

ZZ7 PA Rhyme $\square$ PA Alliteration $\quad$ DIV PA Blending

PA Segmentation

Figure 3. Phonological awareness in children with reading ages of less than 7 and greater than 7 years
The correlations indicate a significant relationship between rhyme awareness and blending and the levels of reading achievement of the children. However, the interpretation of this could be that more reading experience increases phonological awareness and in particular phonemic awareness as illustrated by the blending scores. The measures of alphabetic skills, Seymour nonword reading and spelling, only correlate significantly with the blending scores suggesting that suggesting that it is phonemic awareness - the child's ability to hear or manipulate all the phonemes in words - not more general phonological awareness such as rhyme, that is necessary for the development of an alphabetic strategy.

\section{Comparison between groups}

The children were divided into low and high scorers on the BAS reading test in order to determine any group differences for phonological awareness, using a Mann-Whitney U test. This was repeated with high and low scorers on the digit span test.

Scores on the four measures of phonological awareness were compared between participants with a reading age of less than 7 years $(n=8)$ and higher than 7 years $(n=6)$. Children with a reading age higher than 7 years scored higher on all measures of phonological awareness (see Figure 3 ) although this difference only reached significance on the blending task $(U(6,8)=$ $8.5, p=.043)$.

Comparisons of phonological awareness between the children with a digit span of less than $4(n=6)$ and $>4$ digits $(n=8)$ indicated that children with greater digit spans scored higher on all measures of phonological awareness although the difference only reached significance on the alliteration task $(U(6,8)=$ $6.5, p=.02)$.

\section{Discussion}

Children with Down syndrome were found to have measurable levels of phonological awareness. This result challenges the findings of Cossu et al. (1993) and Evans (1994) and supports the hypothesis that literate children with Down syndrome would display measurable levels of phonological awareness.

A significant positive relationship was found between reading and spelling competence and awareness of phonemes. This relationship remained significant when the effects of age and digit span were partialled out and supports the authors' hypothesis and previous results of Bradley and Bryant (1985). The nature of the 
relationship between phonological awareness and reading ability cannot be resolved without longitudinal data. However, as the children in this study demonstrated a wide range of reading ability it was possible to examine and compare the phonological awareness of children with reading ages ranging from 6 to 9 years. It was found that children with reading ages of 7 years and above demonstrated better awareness of phonemes than those with reading ages of less than 7 years.

Ability to read and to spell non-words was found to positively correlate with phoneme blending. However, it was found that some children demonstrated high levels of phonological awareness without being able to decode nonwords. This suggests that awareness of phonemes may be necessary but not sufficient for acquiring a decoding strategy. Surprisingly, no significant correlation was found between awareness of phonemes and reading of non-words. However, on examination of the data it became evident that although those children who could read non-words showed higher levels of phonological awareness, some children who scored highly on tasks of phonological awareness were unable to read non-words. This may have prevented the positive correlation reaching significance.

All children with decoding skills (i.e. those who scored on the nonword reading and spelling tasks) demonstrated relatively high levels of phonological awareness, thus supporting the findings of Fowler et al. (1995) and challenging those of Cossu et al. (1993). Therefore although Cossu et al. found that children with Down syndrome read nonwords in the absence of phonological awareness, it can be suggested that their measures were insensitive and that the awareness of phonemes was masked by cognitive limitations.

As expected, children with digit spans of greater than 4 were found to score higher than children with lesser spans, on tasks of phonological awareness. However this difference was only significant on the task of alliteration. It is possible that the discrepancies were prevented from reaching levels of significance on the other tasks of phonological awareness because of the relatively small sample size and the wide variability in scores obtained by the children.

Significant positive correlations were found between alliteration and digit span and between segmentation and age. It is acknowledged that all tasks rely on general cognitive abilities to some extent. This finding reiterates the importance of Byrne's (1993) warning that cognitive limitations can mask the true ability of children with Down syndrome.

It is important to note that not all four tasks of phonological awareness were found to significantly positively correlate with each other. This indicates that the four tasks of phonological awareness may be tapping different skills. Due to time considerations and a limited sample of children with Down syndrome, the tasks were not piloted. They therefore lack validity and reliability and may not tap the skills which they are designed to measure. The task of phoneme blending was found to significantly positively correlate with word reading, word spelling, nonword spelling and WORD com- prehension tasks. Therefore it is suggested that this task may be the most reliable measure of awareness of phonemes. The tasks should, of course, be administered to other samples of children on a number of occasions to ensure that they are reliable and valid.

The children's performance on the phonological awareness tasks would be expected to be higher, given that their mean reading and spelling ages are 7 years 2 months. Their limited success with the alphabetic tasks, suggests that they are more dependent on the use of logographic strategies in their reading than would be typical at this reading age. This finding is supported by the work of Kay-Raining Bird, Cleave and McConnell (2000) who also report that phonological awareness and word attack skills do not keep pace with word recognition abilities in these children (p.319).

Teachers should be aware that helping children with Down syndrome to acquire alphabetic skills should be a priority, but that their difficulties may be a consequence of their hearing and auditory short-term memory difficulties (Jarrold \& Baddeley, 2001; Buckley \& Bird, 2001).

Lastly, care must be taken when generalising results to other children with Down syndrome. Children with Down syndrome vary greatly in the extent to which their learning disability affects them, but they also vary greatly in the support they have received from the educational authorities. This sample of children had all received early reading instruction and support from the Sarah Duffen Centre, Portsmouth. The children also attended mainstream primary schools from intake level. Therefore these children may not be representative of children with Down syndrome, but rather demonstrate the level of ability which is possible when children receive early reading instruction.

In conclusion, past research concluded that children with Down syndrome learnt to read in the absence of awareness of phonemes (Cossu et al., 1993; Evans, 1994). However, in this study, 9 of the 14 children achieved scores well above chance levels on the tasks of phonological awareness. Awareness of phonemes (blending task) was found to correlate positively with all measures of reading and spelling competence and the ability to use an alphabetic spelling strategy. This implies that the tasks used in previous studies were insensitive measures in which the children's cognitive abilities may have masked their phonological awareness.

\section{Acknowledgements}

Many thanks to the children and parents who generously gave up their time to travel to the Sarah Duffen Centre and take part in the study. Thanks go to Dr. John MacDonald for statistical advice.

\section{Correspondence}

Helen Fletcher, 8 Burness Close, Uxbridge, Middlesex, UB8

2PZ・Email: Helen@Fletch25.freeserve.co.uk 


\section{References}

Bradley, L. \& Bryant, P. (1985) Rhyme and reason in reading and spelling. International Academy for Research in Learning Disabilities Monographs No.l. Ann Arbor: University of Michigan Press.

Bryant, P. \& Bradley, L. (1985) Children's Reading Problems. Oxford: Basil Blackwell.

Buckley, S. \& Bird, G. (2001) Memory development for individuals with Down syndrome. Portsmouth, UK: Down Syndrome Educational Trust.

Buckley, S., Emslie, M., Haslegrave, G. \& LePrevost, P. (1986). The Development of Language and Reading Skills in Children with Down Syndrome. Portsmouth: Portsmouth Down Syndrome Project.

Byrne, A. (1997). The Development of Reading Skills in Children with Down Syndrome. Unpublished Doctoral Dissertation, University of Portsmouth.

Byrne, B. (1993). Learning to read in the absence of phonemic awareness? A comment on Cossu, Rossini and Marshall (1993). Cognition. 48, 285-288.

Cardoso-Martins, C. \& Frith, U. (1997) Phonological Awareness and Reading Ability in Down Syndrome. Poster presented at the 2nd International Conference on Language and Cognitive Development in Down Syndrome, Portsmouth, 8th - 10th 1997.

Cossu, G., Rossini, F. \& Marshall, J. C. (1993). When reading is acquired but phonemic awareness is not: A study of literacy in Down Syndrome. Cognition, 46, 129-138.

Cupples, L. \& Iacono, T. (2000). Phonological awareness is related to reading skill in children with Down syndrome. Journal of Speech, Language, and Hearing Research. 43, 595-608.

Evans, R. (1994). Phonological awareness in children with Down syndrome. Down Syndrome: Research and Practise, 2 (3) 102-105.

Fowler, A. E., Doherty, B. J. \& Boynton, L. B. (1995) The basis of reading skill in young adults with Down syndrome. In L. Nadel, \& D. Rosenthal, (1995). Down Syndrome: Language and Learning. New York: Wiley.

Frith, U. (1985) Beneath the surface of developmental dyslexia. In K.E. Patterson, J.C. Marshall, \& M. Coltheart, (Eds.). Surface Dyslexia: Neuropsychological and Cognitive Studies of Phonological Reading. London: Lawrence Erlbaum Associates.

Gathercole, S. \& Baddeley, A. (1993). Working Memory and Language. Hove: Lawrence Erlbaum Associates.

Gross, J. \& Garnett, J. (1995) Sound Beginnings: The LDA Phonological Awarenss Training Pack. Wisbech, UK: LDA.

Jarrold, C \& Baddeley, A.D. (2001) Short-term memory in Down syndrome: Applying the working memory model. Down Syndrome Research and Practice, 7(1), 17 - 23.

Kay-Raining Bird, E., Cleave, P.L. \& McConnell, L. (2000) Reading and phonological awarenss in children with Down syndrome: A longitudinal study. American Journal of Speech-Language Pathology, 9, 319-330.

Morais, J., Cary, L., Alegria, J. \& Bertelson, P. (1979). Does awareness of speech as a sequence of phones arise spontaneously? Cognition, 7, 323-331.
Morton, J. \& Frith, U. (1993). What lesson for Dyslexia from Down syndrome? Comments on Cossu, Rossini and Marshall (1993). Cognition, 48, 289-296.

Read, C., Zhang, Y., Nie, H. \& Ding, B. (1986). The ability to manipulate speech sounds depends on knowing alphabetic spelling. Cognition, 24, 31-44.

Seymour, P. H. K. \& Elder, L. (1986) Beginning reading without phonology. Cognitive Neuropsychology, 3, 1-36.

Yopp, H. K. (1988). The validity and reliability of phonemic awareness tests. Reading Research Quarterly, $23,159-177$. 